Rose Bradford ${ }^{15}$ and also Pick ${ }^{4}$ have drawn attention to the comparative immunity of officers to war nephritis, and the former has also reported the complete immunity of the Indian troops to this disease. The Indian troops suffered from all other war diseases, including bronchitis, but not from nephritis. These facts suggest that British officers and Indian troops share something in common, or avoid something equally, which influences the onset of war nephritis. In the British Army officers and men at the front line live under almost similar conditions : all drink from the same water-supplies; all breathe the same polluted air and live under the same unpleasant conditions. The officers do, however, eat fresh food. Even in the trenches during the Somme battle salads and fruit were seen in officers' dug-outs. When out at rest officers buy fresh food and vegetables and are able often to obtain new milk; in other words, they supplement their rations. This applies equally well to officers living on the lines of communication or at the base; probably they have a "ration mess," but certainly they supplement their rations with fresh food. The soldier, however, does not do this. He draws his rations, but has little or no opportunity, even if he desires to do so, of purchasing fresh eatables. The Indian troops were accustomed to eat fresh meat newly killed and not the frozen or canned meat of European troops. They had fresh milk and not the tinned variety. So, in common with British officers, the native troops obtained fresh food.

It is perhaps a suggestive fact that in the urines of cases of beri-beri Hewlett and De Korté ${ }^{16}$ found a body similar in appearance to the endotbelial cell. We, too, have found endothelial cells in the urines of cases of beri-beri imported into France with Asiatic labour.

The hæmaturia of war nephritis, which is often persistent, is reminiscent of that which occurs in mild cases of scurvy. It is interesting to note that the majority of cases had been in this country, and restricted living rations, for about seven months. Experience of work with front-line battalions has impressed upon both of us the frequency of boils and skin eruptions, the scorbutic origin of which is suggested by their great improvement when a lime-juice ration was instituted. The objection may possibly be raised that the maximum incidence of the disease corresponds with the summer weather and the fruit season; this is met by the fact that fresh fruit and vegetables in France are beyond the financial resources or cooking abilities of the average soldier.

Careful consideration of all the views discussed above leads us to think that war nephritis may be attributed to some error in metabolism due to dietary deficiency. Our own observations would suggest the possibility of this, although we feel that our hypothesis is as yet by no means proved.

We wish to express our thanks to Major A. B. Smallman, D.S.O., R.A.M.C., for his kindness in affording us access to the publications of other writers upon this subject.

Bibliography.-1. Brit. Med. Jour., April 8th, 1916, p. 526. 2. Proceedings Roysl Society of Medicine, Section of Patbology. Dec. 5th, 1916. 3. THE LANCET, July 1st, 1916. 4. Münch. med. Woch. Feb. Ist, 1916 ; quoted by Brit. Med. Jour., August 19th, 1916 5. Quarterly Journal of Medicine, vol. ix, No. 34, January, 1916 6. Austro-German Medical Congress at Warsaw, ThE LANCET, July lst 1916. 7. Ibid. 8. Abercrombie: Journal of the Royal Army Medical Corps, August, 1916. 9. Wien. med. Woch., Oct. 13th, 1915; Brit. Med. Jour., Jan. 8th, 19i6. 10. M ickenzie Wallis: Journal of the Rinal Army Medical Corps, August, 1916. 11. Brit. Med. Jour., Dec. 16th, 1916. 12 Dunn: Medical Snciety of London, Nov, 13th, 1916; reported in The Lancet. Nov, 18th, 1916. 13. The Lancet, Sept. 9th, 1916. 14. Gaud and Mauriac: Paris Méd., April 15 h, 1916; reported in Brit. Med. Jour. May 13th. 1916. 15. Rose Bradford: Quarterly Journal of Medicine, January, 1916. 16. Journal of Tropical Medicine, Oct. 1st, 1907 , p. 315 .

WOMEN AND The INDIAN MEDICAL SERVICE.-The Government of India is said to be considering the advisability of employing a certain number of medical women in the Indian hospitals with a view to setting free more medical officers for military service. The names of medical women prepared to offer their services are being called for.

Medical Dispensary and Workhouse Satiartes IN IRELAND.-The Lurgan board of guardians have (Sept. 6th) adopted a graded scale of salaries for the medical officers of that union. The new scale means that the sqlary of Dr. W. W. Duff (Aghalee) will be increased from $£ 100$ to $£ 145$; Dr. S. Agnew's (Lurgan), £123 to £160; Dr. H. Reid's (Montiaghs), £ll0 to £l35; Mr. T. H. Brownrigg's (Moira) $£ 106$ to £150; Mr. J. L. Rowlett's (Portadown), £110 to £160; Dr. G. Dougan's (Tartaraghan), £100 to £150; Dr. W. Frier's (Waringstown), $£ 100$ to $£ 150$; Dr. J. S. Darling's (Workhouse), $£ 130$ to $£ 155$.

\section{A REPORT ON THE}

TREATMENT OF ENTAMCEBA HISTO. LYTICA "CARRIERS" WITH EMETINE BISMUTH IODIDE,

GIVING A COMPARISON BETWEEN THE KERATIN-COATED TABLOIDS AND SALOL-COATED PILLS.

Bx D. G. LILLIE, M.A. CAMB.

LATE BIOLOGIST TO THE BRITISH ANTARCTIC EXPEDITION, 1910; ANI)

S. SHEPHEARD, M.R.C.S., L.R.C.P. LOND., CAPTAIN, R.A.M.C. (T.)

(A Report to the Medical Researoh Committee from the Mont Dore Military Hospital, Bournemouth.)

THE treatment of the 104 cases dealt with in this report was carried out in a special ward set apart for the purpose. The cases were under the care of one medical officer in order to keep the conditions of treatment as uniform as possible. Both forms of the drug were given in doses of 3 grains per day for 12 consecutive days without any additional treat ment. The tabloids and pills were given entire as a full dose during breakfast. We have considered a case to be cured when he has had at least six or seven negative tests over a period of not less than seven weeks from the termination of his course of treatment. The last one or two tests were made at the Barton Convalescent Depôt. The great majority of the cases, however, had many more tests: some were examined almost daily and were under observation for nearly three months after the end of treatment.

First Course of Treatment.

The number of men treated with one course of the keratincoated tabloids supplied by Burroughs, Wellcome and Co. was 79 and the number of men who were given one course of the salol-coated pills prepared by Allen and Hanburys was 25.

We have found it advisable to divide these two sets of men into those who had injections of emetine hydrochloride before entering hospital and those who did not receive this treatment. The results are as follows:-

Cases without emetine injections.-Forty-five men were given one course of the keratin-coated tabloids and 29 were cured-i.e., 64.5 per cent.

Seventeen men were given one course of the salol-coated pills and 12 men were cured-i.e., 70 per cent.

Cases with emetine injections. - Thirty-four men were given one course of the keratin-coated tabloids and 12 were curedi.e., 35 per cent.

Eight men were given one course of the salol-coated pills and five were cured-i.e., 62 per cent.

Second course of treatment.-Twenty-four men who had relapsed after one course of the keratin-coated tabloids were given a second course of the same form of the drug and four were cured-i.e., 16.6 per cent.

Fourteen men who had relapsed after two or three courses of the keratin-coated tabloids were treated with one course of the salol-coated pills and four were cured-i.e., 28.5 per cent.

\section{Effect of the Time Interval between the Onset of Disease and} Treatment.

The object of this part of the inquiry was to ascertain whether those cases which relapsed after treatment could be shown to be "carriers" of longer standing, in whom $E$. histolytica had become better established and consequently harder to cure. In order to make certain, as far as possible, that the onset of disease referred to was that of amcebic dysentery, only those patients were included under this section whose blood failed to agglutinate $B$. dysenteria Shiga and $B$. dysenteria Flexner.

Cases without emetine injections.-Out of 19 men who were cured by emetine bismuth iodide (E.B.I.) 7 (36.8 per cent.) had an interval of over 20 weeks between the date of onset of their dysentery symptoms and the date on which they received E.B.I. treatment. The average interval for the 19 cases was 19 weeks.

Out of 14 men who relapsed after treatment with E.B.I. 8 (50.7 per cent.) had an interval of over 20 weeks between the dates of onset and treatment. The average interval for the 14 cases was 22 weeks. 
Cases with emetine injections.-Out of 12 men who were cured by E.B.I. treatment $10(80.3$ per cent.) had an interval of over 20 weeks between dates of onset and treatment. The average interval for the 12 cases was 29 weeks.

Out of 14 men who relapsed after treatment with E.B.I. 11 (78.5 per cent.) had an interval of over 20 weeks between the dates of onset and treatment. The average interval of the 14 cases was 42 weeks.

\section{Influence of Other Fractors.}

Vomiting.-Out of 46 cases cured by the keratin-coated tabloids 40 vomited during treatment-i.e., 87 per cent. The total number of days on which the 40 vomited was 285 . The average number of vomiting days for those men who vomited gives a convenient coefficient for purposes of comparison-i.e., 7 .

Out of 21 cases cured by the salol pills 14 vomited during treatment-i.e., 66 per cent. The 14 who vomited had 53 vomiting days-i.e., vomiting coefficient 3.7.

Out of 45 cases who relapsed after the keratin-coated tabloids 37 vomited during treatment-i.e., 82 per cent. The 37 who vomited had 333 vomiting days--i.e., vomiting coefficient 9.

Out of 18 cases who relapsed after the salol-coated pills 14 vomited during treatment-i.e., 78 per cent. The 14 who vomited had 63 vomiting days-i.e., vomiting coefficient 4.5 . Loss of weight.-. Out of 46 men cured by keratin-coated tabloids 24 lost weight--i.e., 52 per cent.

Out of 21 men cured by salol-coated pills 7 lost weighti.e., 33 per cent.

Out of 45 men who relapsed after keratin-coated tabloids 18 lost weight-i.e., 40 per cent.

Out of 10 cases who relapsed after salol-coated pills 5 lost weight-i.e., 50 per cent.

Effect of age on curative results.-The average age of 38 cases cured by keratin-coated tabloids was $27 \cdot 6$ years. 11 men out of the 38 were over 30 years of age.

The average age of 38 cases which relapsed after keratincoated tabloids was 28.9 years. 11 men out of the 38 were over 30 years of age.

The average age of 17 cases cured by salol-coated pilla was 28.7 years. 4 of the 17 were over 30 years of age.

The average age of 17 cases which relapsed after salolcoated pills was 28.4 . 5 of the 17 were over 30 years of age. Effect of age on vomiting.-36 men under 25 years treated with keratin-coated tabloids had 271 vomiting days-i.e., vomiting coefficient $7 \cdot 5$.

26 men over 30 years treated with the same tabloids had 157 romiting days-i.e., vomiting coefficient 6.

7 men over 40 years treated with the same tabloids had 22 vomiting days-i.e., vomiting coefficient $3 \cdot 1$.

\section{Conolusions.}

The conclusions which we think may be drawn from the foregoing facts are as follows :-

1. (a) That " carriers" of E. histolytioa who had not had any injections of emetine hydrochloride were cured to the extent of 78 per cent. by two courses of the salol-coated emetine bismuth iodide pills. (b) In the case of men who had had emetine injections 728 per cent. were cured by two courses of the salol-coated pills. (c) In the case of men who had not had emetine injections 70 per cent. were cured by two courses of the keratin-coated tabloids. (d) In the case of men who had had emetine injections 45.4 per cent. were cured by two courses of the keratin-coated tabloids.

The difference between the percentages in $(a)$ and $(b)$ are within the range of experimental error and need not be considered. But in (c) and (d) the difference is too great to be ignored. This difference may be due to variation in the quality of the keratin-coated tabloids, but such a defect would be common to both cases which had received injections of emetine and those which had not. It is generally admitted that certain "carriers" of $E$. histolytica are not cured by emetine in any form, and it may be, as $\mathrm{Mr}$. Dobell suggests, that these cases become segregated in $(d)$. It seems possible that the difference in the two percentages may be due to the injections of emetine rendering the "carriers" less liable to be cured by E.B.I.

For comparison with the above percentages of cures by a maximum of 72 grains of E.B.I. carried out in the special ward, we give the number and percentage of cures in the other wards of this hospital. The number of grains of E.B.I. which these cases received varied from 36 to 200 . A case was regarded as cured after not less than 5 negative examinations over a period of not less than 5 weeks after the end of treatment. The last test was made at the Barton Convalescent Depôt. Ont of 160 cases treated 142 were cured-i.e., $88 \cdot 7$ per cent.
2. There is no evidence that the length of time between the dates of onset of dysentery symptoms and the treatment has any effect upon the chances of cure by E.B.I.

3. There is no ground for the belief that the vomiting diminishes the chance of cure by the E.B.I. treatment. There is nearly as much vomiting among the cases which are cured as among those which relapse.

4. The age of the patient has no effect upon the chance of cure by the drug. But there is evidence to show that men over 40 years of age vomit less while undergoing treatment.

5. The salol-coated pills are a distinct improvement upon the keratin-coated tabloids from a curative point of view. They also cause less vomiting and loss of weight.

In conclusion, we express our hearty thanks to Temporary Honorary Captain A. C. Inman, R.A.M.C., Mr. W. O. Redman King, and Mr. A. G. Thacker for making some of the examinations for us and for help in many ways. To Lieutenant-Colonel T. H. F. Clarkson, R.A.M.C., officer commanding, Mont Dore Military Hospital, Bournemouth, we are indebted for permission to publish this report.

\section{THE TREATMENT OF FUNCTIONAL CONTRACTURE BY FATIGUE.}

\author{
BY E. F. REEVE, M.B., B.S. LoND., M.R.C.S., \\ L.R.C.P. LOND.,
}

CAPTAIN (TEMPORARY) R.A.M.C.; MILITARY hospital, MaghULI.

ONE of the most striking and obstinate of the objective disabilities displayed in the functional war neuroses is muscular contracture. The majority of the functional disorders met with are due to the absence or diminished activity of a normal function, and are easily and rapidly curable by suggestion and re-educative measures. Contractures, on the other hand, form part of a group of cases dependent not so much upon the absence of a normal function as upon its excessive and disordered activity. As a general rule, they are not very amenable to treatment by suggestion and re-education.

The object of this paper is to describe a method which the writer has used in dealing with this type of war neurosis. $\mathrm{He}$ has seen no reference to this treatment in the literature, and, as far as he knows, it has not been used by others. The advantage of the method is that once a diagnosis of functional contracture has been made no special experience is required in the carrying out of the treatment.

In the cases which have come under my care this treatment has invariably proved successful in the course of a few days, although most of them had been treated without benefit for long periods in various hospitals by other methods. The principle of the treatment simply consists in producing a condition of fatigue in the musoles responsible for the contraoture. This is obtained by continuous passive movements in a direction opposed to the normal action of the contracted muscles. A good deal of force is often necessary in the early stages of the treatment, but as time goes on the spasmodic return of the muscles becomes slower and weaker until finally a limp, toneless, and fatigued condition is brought about. The offending muscles are then no longer able to produce the deformity for which they were responsible.

In the case of the more powerful muscles it may be necessary to continue the forcible movements for many hours before the condition of fatigue results, and relays of men must be "told off" to relieve each other, so that the muscles may get no opportunity of recovering the ir tone. In my own wards I have been in the habit of getting patients to assist in the work, and in particular I find it helpful to make use of those who have themselves been cured by the same kind of treatment.

It is always my custom carefully to explain matters in the simplest language to the patient before commencing the treatment. I describe to him the nature of a spasm and tell him that once it is relieved he will be able to bring into action opposing muscles which are now unable to perform their functions on account of this persistent spasmodic contraction.

\section{Lulustrative Cases.}

It will be seen from the description of the cases given below that many of them have been suffering from these contractures for a great length of time. Almost every case has 